\title{
Trapping at the Solid-Gas Interface: Selective Adsorption of Naphthalene by Montmorillonite Intercalated with a Fe(III)- Phenanthroline Complex
}

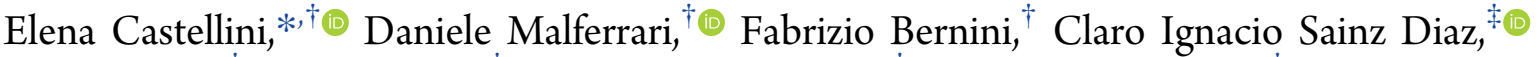

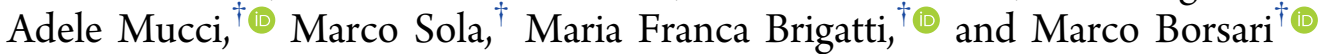 \\ ${ }^{\dagger}$ Department of Chemical and Geological Sciences, University of Modena and Reggio Emilia, Via Campi 103, I-41125 Modena, Italy \\ ${ }^{\ddagger}$ Instituto Andaluz de Ciencias de la Tierra (CSIC-UGR), Av. de las Palmeras, 4, 18100-Armilla, Granada, Spain
}

\section{Supporting Information}

\begin{abstract}
In this study, stable hybrid materials (Mt-Fe(III)Phen), made by the $\mu$-oxo $\mathrm{Fe}(\mathrm{III})$ - phenanthroline complex $\left[\left(\mathrm{OH}_{2}\right)_{3}(\mathrm{Phen})\right.$ $\left.\mathrm{FeOFe}(\mathrm{Phen})\left(\mathrm{OH}_{2}\right)_{3}\right]^{4+}(\mathrm{Fe}(\mathrm{III})$ Phen) intercalated in different amounts into montmorillonite $(\mathrm{Mt})$, were used as a trap for immobilizing gaseous benzene and naphthalene and their mono chloro-derivatives at 25 and 50 ${ }^{\circ} \mathrm{C}$. The entrapping process was studied through elemental analysis, magic angle spinning NMR spectroscopy, thermal analysis, and evolved gas mass spectrometry. Naphthalene and 1-chloronaphthalene were found to be immobilized in large amount at both temperatures. Molecular modeling allowed designing of the structure of the interlayer in the presence of the immobilized aromatic molecules. Adsorption is affected by the amount of the Fe complex hosted in the interlayer of the entrapping hybrid materials. On the contrary, under the same conditions, benzene and chlorobenzene were not adsorbed. Thermal desorption of naphthalenes was obtained under mild conditions, and immobilization was found to be reversible at least for 20 adsorption/desorption cycles.
\end{abstract}

\section{INTRODUCTION}

Monocyclic and polycyclic aromatic molecules are produced by several industrial and human activities, including the combustion processes of vehicles. Many efforts have been devoted to the production of materials able to remove the pollutants through immobilization processes or catalytic degradation. Several are presently available, but most lack selectivity. In addition, they are successfully operated mainly in solution. Only a few materials, such as zeolite HZSM- $5^{1}$ and diatomite-based ceramic monoliths coated with silicalite- $1{ }^{2}$ trap effectively aromatic molecules in the gas phase, and a number of challenges related to selectivity are to be tackled, which are complicated by the low partial pressure of these compounds in the flue gas. Natural and engineered zeolites are extensively employed as catalysts in a variety of reactions involving benzene and naphthalene. For example, zeolites are commercial catalysts currently utilized in refineries to remove benzene from gasoline by alkylation with olefins (BenzOUT process ${ }^{3}$ ). Other reactions of benzene are catalyzed by zeolites, such as self-alkylation and hydrogenation, ${ }^{4}$ oxidation to obtain phenol, $^{5}$ and hydrogenation to produce cyclohexane. ${ }^{6}$ Immobilization followed by a catalytic reaction implies that the target aromatic species is transformed into different final molecules and the overall process is irreversible, thus desorption does not restore the starting species. Simple adsorption, instead, allows the aromatic molecule to retain its structure and the recovery of the chemical compound. For example, activated carbon is largely employed as an industrial adsorbent for gases because of its effectiveness and low cost. ${ }^{7}$ However, this material shows many drawbacks as the limited thermal stability and poor versatility. More importantly, the adsorbed organic gas molecules are confined in the slitlike micropores, and this could result in a difficult desorption and regeneration. ${ }^{2}$ Moreover, in some cases, immobilization partly occurs via chemical adsorption, which changes the functional groups and the structure of activated carbon. For example, Guo et al. ${ }^{8}$ found that after chlorobenzene adsorption, the lactone and quinone groups on activated carbon decreased, and the structure of activated carbon slightly changed. In addition, activated carbon, also after specific treatments, is poorly selective.

Here, we have investigated the effectiveness of a hybrid material made by the intercalation of the $\mu$-oxo di-fac-[triaqua$\left(1,10\right.$-phenanthroline- $\left.k^{2} N, N^{\prime}\right)$-iron(III) $]^{4+}, \quad\left[\left(\mathrm{OH}_{2}\right)_{3}(\right.$ Phen $)$ FeOFe(Phen) $\left.\left(\mathrm{OH}_{2}\right)_{3}\right]^{4+}$ complex (Fe(III)Phen), ${ }^{9}$ onto montmorillonite ( $\mathrm{Mt}-\mathrm{Fe}(\mathrm{III}) \mathrm{Phen}$ hereafter) to immobilize some selected paradigmatic aromatic molecules from the gas phase: benzene, chlorobenzene, naphthalene, and 1-chloronaphtha-

Received: February 5, 2019

Accepted: April 17, 2019

Published: April 29, 2019 
lene. In previous papers, this hybrid material ( $\mathrm{Mt}-\mathrm{Fe}$ (III)Phen) was characterized, unraveling that the $\mathrm{Fe}(\mathrm{III})$ Phen complex has a structuring effect on the interlayer because of the presence and orientation of extended aromatic regions of the ligand; ${ }^{10,11}$ then this hybrid material was proved effective in trapping volatile sulfur compounds, aliphatic thiols and $\mathrm{H}_{2} \mathrm{~S} .{ }^{12,13}$ In this case, the entrapping mechanism for thiols and $\mathrm{H}_{2} \mathrm{~S}$ is controlled by the redox and coordination properties of the metal center. In the present work, on the other hand, we investigated the ability of the interlayer structured by the Fe(III)Phen complex, which bears two coordinated planar phenanthroline ligands almost parallel to each other, ${ }^{9}$ to capture specific aromatic compounds, thanks to the polycyclic nature of the Phen ligand.

Here, benzene, chlorobenzene, naphthalene, and 1-chloronaphthalene trapping by $\mathrm{Mt}-\mathrm{Fe}$ (III)Phen was studied to understand if a relationship exists between the entrapping efficiency and the size of the aromatic moiety and to test the effect of a halogen substitution. Removal of such pollutants from the environment would be a result of great social and industrial significance. ${ }^{14}$

\section{EXPERIMENTAL SECTION}

2.1. Materials. Mt STx-1a from the Clay Minerals Society (The Clay Minerals Society, Source Clays Repository, University of Missouri, Columbia, MO) was characterized elsewhere. $^{15,16}$ It was used "as received", avoiding any purification or exchange process intended to obtain a homogeneous counterion, as efficiency of this clay mineral in the adsorption of the Fe(III)Phen complex was already proved when used "as it is". 10,12,13

All the chemicals used for preparation of the adsorbent material were of analytical grade (purity $>99 \%$ ) and purchased from Carlo Erba $\left(\mathrm{Fe}_{2}\left(\mathrm{SO}_{4}\right)_{3} \cdot 8 \mathrm{H}_{2} \mathrm{O}\right.$ and $\mathrm{NaOH}$ pellets) or from Sigma-Aldrich (1,10-phenanthroline $\mathrm{C}_{12} \mathrm{H}_{8} \mathrm{~N}_{2}$, Phen). The aromatic molecules tested for adsorption in the gas phase were as follows: benzene $99.0 \%$ (AnalaR, analytical reagent, benz hereafter), chlorobenzene $\geq 99.5 \%$ (Fluka, Clbenz hereafter), naphthalene scintillation grade (BDH Laboratory reagents, naph hereafter), and 1-chloronaphthalene $90 \%$ (Aldrich Chemie, Clnaph hereafter).

2.2. Methods. 2.2.1. Preparation of Mt Intercalated with Different Amounts of the Fe(III)Phen Complex: Mt-Fe(III)Phen Materials. The solutions of $\left[\left(\mathrm{OH}_{2}\right)_{3}(\mathrm{Phen}) \mathrm{FeOFe}-\right.$ (Phen) $\left.\left(\mathrm{OH}_{2}\right)_{3}\right]^{4+}(\mathrm{Fe}(\mathrm{III}) \mathrm{Phen})$ were prepared by dissolving $\mathrm{Fe}_{2}\left(\mathrm{SO}_{4}\right)_{3} \cdot 8 \mathrm{H}_{2} \mathrm{O}$ in aqueous Phen solutions (typically $2 \div 12$ $\mathrm{mM}$ ) in order to have a $1: 1 \mathrm{Fe}(\mathrm{III}) /$ Phen molar ratio. ${ }^{10}$ The $\mathrm{Fe}(\mathrm{III})$ Phen solutions $(20 \mathrm{~mL})$ in the $1-6 \mathrm{mM}$ range of concentration were mixed with $100 \mathrm{mg}$ of $\mathrm{Mt}$ to form the corresponding suspensions. The suspensions were shaken at $250 \mathrm{rpm}$ in an orbital incubator (Stuart Scientific Orbital Incubator SI50) at $20{ }^{\circ} \mathrm{C}$ for $30 \mathrm{~min}$ using a Haake $\mathrm{k} 20$ thermocryostat and then kept in the thermostated incubator. After the solid-liquid separation, the supernatant was removed with a pipette. The solids were washed several times with distilled water and dried at $30^{\circ} \mathrm{C}$. They have different levels of interlayer saturation by the filling of complex molecules, and all constitute the Mt-Fe(III)Phen adsorbent materials. Quantification of the amount of the intercalated complex was obtained by UV-vis measurements (JASCO V-570 Spectrophotometer) performed on the different supernatants, previously centrifuged at $14000 \mathrm{rpm}$ (Thermo mod. Espresso) for $1 \mathrm{~min}$ to remove residual clay traces. $q_{\text {complex }}$ is defined as the content in the iron complex of the Mt-Fe(III)Phen material, expressed as moles of Fe(III)Phen per $100 \mathrm{~g}$ of Mt$\mathrm{Fe}(\mathrm{III}) \mathrm{Phen} ; q_{\text {complex }}$ ranges from 0.005 to 0.038 (saturation limit of $\mathrm{Mt}$ ) moles of $\mathrm{Fe}(\mathrm{III}) \mathrm{Phen} / 100 \mathrm{~g} \mathrm{Mt}-\mathrm{Fe}(\mathrm{III})$ Phen. ${ }^{10,12,13}$

2.2.2. Immobilization of Aromatic Compounds in the Gas Phase on Mt-Fe(III)Phen at Different $q_{\text {complex }}$ Values. Mt$\mathrm{Fe}$ (III)Phen prepared with $q_{\text {complex }}$ ranging from 0.005 to 0.038 moles of Fe(III)Phen/100 g Mt-Fe(III)Phen was exposed to the vapors of aromatic compounds benz, Clbenz, naph, and Clnaph at 25 and $50{ }^{\circ} \mathrm{C}$ for 1 month. The Mt-Fe(III)Phen adsorbent material $(100 \mathrm{mg})$ was finely dispersed in a glass Petri dish (diameter $5 \mathrm{~cm}$ ) and placed in a sealed glass box in the dark. The aromatic compound (benz, Clbenz, naph, and Clnaph) was placed in a beaker inside the same glass box, which was closed with a sealing cap. The glass boxes were thermostated at 25 and $50{ }^{\circ} \mathrm{C}$ for 1 month. In this way, we can confidently assume that at each temperature, the box was always saturated with the vapor of the aromatic compound at the vapor pressure (ref 17, Table S1, page S2). After 1 month, the elemental analyses were performed on samples to find the maximum amount of the adsorbed aromatic compounds. Hereafter, these materials after exposure to benz, Clbenz, naph, and Clnaph at 25 and $50{ }^{\circ} \mathrm{C}$ will be indicated as Mt-

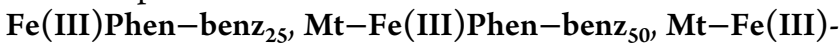
Phen-Clbenz 25 , Mt-Fe(III)Phen-Clbenz 5 , Mt-Fe(III)-

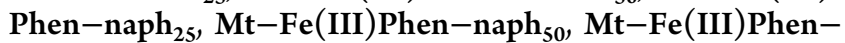
Clnaph $_{25}$, and $\mathbf{M t - F e ( I I I ) P h e n - C l n a p h} \mathbf{5 0}_{50}$. In addition, for the material prepared with the amount of the complex which gives the maximum adsorption capacity, the "best" suffix was introduced: $\mathrm{Mt}-\mathrm{Fe}\left(\right.$ III)Phen-benz $\mathrm{best25}_{\text {, }}$ Mt-Fe(III)Phenbenz $_{\text {best50, }}, \mathrm{Mt}-\mathrm{Fe}$ (III)Phen-Clbenz $\mathrm{best25}$, Mt-Fe(III)Phen-

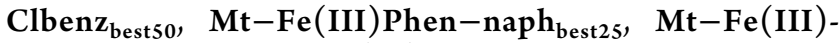

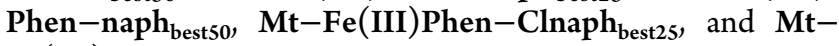
$\mathrm{Fe}$ (III)Phen-Clnaph best50. $_{\text {. }}$ Ph

2.2.3. Kinetics of Immobilization of the Aromatic Compounds in the Gas Phase. Kinetics of immobilization was investigated on $\mathrm{Mt}-\mathrm{Fe}$ (III)Phen showing the maximum immobilization capacity of naph and Clnaph at 25 and $50{ }^{\circ} \mathrm{C}$, respectively $\left(q_{\text {complex }}=0.022\right.$ and 0.025 moles of $\mathrm{Fe}(\mathrm{III}) \mathrm{Phen}$ in $100 \mathrm{~g}$ of $\mathrm{Mt}-\mathrm{Fe}(\mathrm{III}) \mathrm{Phen}$ ), which will be indicated as Mt-

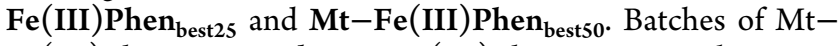

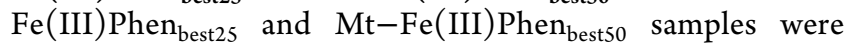
prepared and exposed to the vapors of naph and Clnaph at 25 and $50{ }^{\circ} \mathrm{C}$, respectively, as a function of time in the range 1 $\mathrm{h}$ to 30 days, using the same procedure described in the previous paragraph. The elemental analyses performed on samples at different times allowed to investigate the kinetics of immobilization of the aromatic compounds.

2.2.4. Desorption of Aromatic Compounds from Mt$\mathrm{Fe}\left(\right.$ III)Phen-naph best25 $_{\text {and } \mathrm{Mt}-\mathrm{Fe}(\mathrm{III}) \text { Phen-Clnaph }}$ best25 at Different Temperature Values; Adsorption/Desorption Cycles. Batches of $\mathrm{Mt}-\mathrm{Fe}(\mathrm{III}) \mathrm{Phen}-$ naph $_{\text {best25 }}$ and $\mathrm{Mt}-$

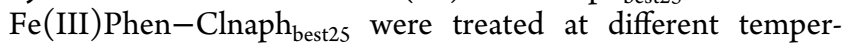
ature values: 160,180 , and $200{ }^{\circ} \mathrm{C}$ for $t=10 \mathrm{~min}$; elemental analysis was performed on the samples after every minute of treatment to measure the residual amount of aromatic compounds as a function of time. Samples were completely desorbed at $T=200{ }^{\circ} \mathrm{C}$, and then they underwent 20 adsorption/desorption cycles (adsorption at $25{ }^{\circ} \mathrm{C}$ for $400 \mathrm{~h}$ and desorption at $200{ }^{\circ} \mathrm{C}$ ); the content in the aromatic compound was checked during the 20 cycles at different times by elemental analysis. 
2.2.5. Elemental Analysis. The elemental analyses (C, N, S) of the samples before and after exposure to the vapors of aromatic compounds were performed by a Carlo Erba elemental analyzer (model 1106) and used to calculate the amount of the adsorbed aromatic compound.

2.2.6. Thermogravimetric Measurements and Analysis of the Evolved Gases with Mass Spectrometry. Thermogravimetric analyses (TGAs) on the samples before and after exposure to the vapors of the aromatic compounds were made with a Seiko SSC 5200 thermal analyzer equipped with a quadrupole mass spectrometer (ESS, GeneSysQuadstar 422) to characterize the gases evolved during the thermal processes (mass spectrometry evolved gas analysis, MS-EGA). Gas sampling by the spectrometer was via an inert, fused silicon capillary system, heated to prevent the condensation of gases. Gas analyses were performed in multiple ion detection (MID) mode to determine the nature of the evolved chemical species with temperature (or time). Background subtraction was used to obtain the point zero conditions before starting MID analysis. Measurements were performed on each air-dried sample under the following experimental conditions: heating rate: $20{ }^{\circ} \mathrm{C} / \mathrm{min}$; heating range: $25-1200{ }^{\circ} \mathrm{C}$; data measurement: every $0.5 \mathrm{~s}$; purging gas: ultrapure helium, flow rate: 100 $\mu \mathrm{L} / \mathrm{min}$. Mass analyses were carried out in multiple ion detection mode measuring the $m / z$ ratios 17 and 18 for $\mathrm{H}_{2} \mathrm{O}$, 28 and 44 for $\mathrm{CO}_{2}, 30$ for $\mathrm{NO}$ and $\mathrm{NO}_{2}, 34$ for $\mathrm{H}_{2} \mathrm{~S}, 46$ for $\mathrm{NO}_{2}$, and 48, 64, and 66 for $\mathrm{SO}_{2}(\mathrm{~m} / z$ is the dimensionless ratio between the mass number and the charge of an ion); secondary electron multiplier (SEM) and FARADAY detector at $1100 \mathrm{~V}$ were employed with $1 \mathrm{~s}$ of integration time on each measured mass. To avoid differences in relative humidity, samples were equilibrated for $15 \mathrm{~min}$ inside the oven at $25{ }^{\circ} \mathrm{C}$ using a $100 \mu \mathrm{L} / \mathrm{min}$ flow of ultrapure helium.

2.2.7. NMR Measurements. NMR spectra were acquired at $300 \mathrm{~K}$ using an AVANCE III HD 600 Bruker spectrometer equipped with a $2.5 \mathrm{~mm} \mathrm{H} / \mathrm{X}$ CPMAS probe operating at 600.13 and $150.90 \mathrm{MHz}$ for ${ }^{1} \mathrm{H}$ and ${ }^{13} \mathrm{C}$, respectively. Samples were packed into $2.5 \mathrm{~mm}$ zirconia rotors and spun at the magic angle. ${ }^{1} \mathrm{H}$ NMR spectra were obtained at 30 or $33 \mathrm{kHz}$ magic angle spinning (MAS) rate, using DEPTH sequence ${ }^{18}$ in order to remove baseline distortions, at $125 \mathrm{kHz}$ spectral width, $10 \mathrm{~s}$ relaxation delay, $2.3 \mu \mathrm{s} 90^{\circ}$ pulse, $4 \mathrm{k}$ data points, and 32 scans. The empty rotor ${ }^{1} \mathrm{H}$ spectrum was subtracted to compensate for background effects.

Cross-polarization-MAS (CP-MAS) ${ }^{13} \mathrm{C}$ NMR spectra were obtained at $16 \mathrm{kHz}$ MAS rate, using the standard Bruker CP sequence with $139 \mathrm{kHz}$ spectral width, 1 s relaxation delay, 2.3 $\mu \mathrm{s} 90^{\circ}{ }^{1} \mathrm{H}$ pulse, radio frequency field strength of about $62 \mathrm{kHz}$ for Hartmann-Hahn match, $0.2 \mathrm{~ms}$ contact time, $4 \mathrm{k}$ data points, and $28 \mathrm{k}-32 \mathrm{k}$ scans.

All chemical shifts were referenced by adjusting the spectrometer field to the value corresponding to $38.48 \mathrm{ppm}$ chemical shift for the deshielded line of the adamantane ${ }^{13} \mathrm{C}$ NMR signal, as previously reported. ${ }^{19}$

2.2.8. Molecular Modeling. A $3 \times 2 \times 1$ supercell of Mt was created with one intercalated $\mathrm{Fe}$ (III)Phen complex with the phenanthroline rings parallel with the clay (001) surface and 12 water molecules per Fe complex, 6 water molecules coordinated with the $\mathrm{Fe}$ atoms and 6 water molecules in the free space between $\mathrm{Fe}$ complexes. This structure was previously optimized by means of quantum mechanical calculations with the density functional theory approximation using SIESTA code, whose details are described elsewhere. ${ }^{11}$
A double supercell was generated, being a $3 \times 4 \times 1$ of $\mathrm{Mt}$ and two $\mathrm{Fe}$ (III)Phen complexes. One of these complexes was rotated in order to place both phenanthroline moieties oriented to the same side maintaining all rings parallel to the clay surface, creating a hydrophobic channel. The distances between the phenanthroline complexes are 7.56-8.25 and 6.58 $\AA$ in the $b$ and $a$ axes directions, respectively (Figure 1).

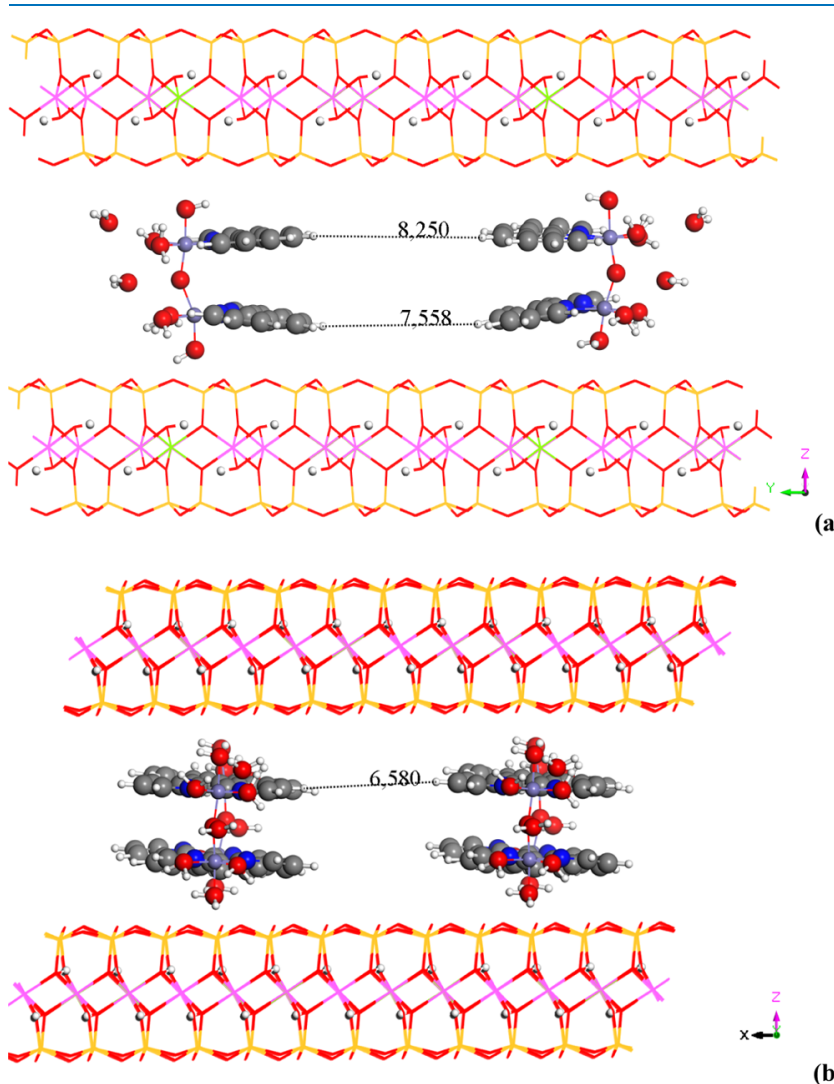

(b)

Figure 1. Molecular structure of the $3 \times 4 \times 1$ supercell of Mt with two $\mathrm{Fe}(\mathrm{III})$ Phen complexes with eight water molecules per $\mathrm{Fe}$ complex, viewed from (010) (a) and (100) (b) planes. The Fe, H, O, $\mathrm{N}, \mathrm{C}, \mathrm{Si}, \mathrm{Al}$, and $\mathrm{Mg}$ atoms are in purple, white, red, blue, gray, ochre, pink, and green colors, respectively.

On the other hand, taking into account the amount of water (2.96\%, see after) found experimentally by TGA in Mt$\mathrm{Fe}$ (III)Phen showing the maximum immobilization capacity of naph at $25{ }^{\circ} \mathrm{C}$ ( Mt-Fe(III)Phen-naph best25 $_{\text {, }}$, eight water molecules were placed per Fe complex, six coordinating the $\mathrm{Fe}$ cations and two water molecules disperse freely between complexes. Periodic boundary conditions were applied for calculations that were based on empirical interatomic potentials using the Universal force field with the Forcite program within the Materials Studio package. ${ }^{20}$ Ewald summation was applied for the Coulomb and van der Waals interactions with a cutoff at $15 \AA$. The atomic charges were calculated with the QEq method ${ }^{21}$ considering that the whole system is neutral, the charge of the clay mineral supercell is $-8 e^{-}$, the charge of each Fe complex without water molecules is $+4 e^{-}$, and each water and naphthalene molecule was neutral.

The adsorption energy was calculated as

$$
\Delta E=E_{\text {adsorption complex }}-\left(E_{\text {adsorbate }}+E_{\text {host }}\right)
$$


where $\Delta E$ (adsorption energy) is the energy involved in the adsorption of the molecule(s) of adsorbate (naphthalene) in the double supercell of $\mathrm{Mt} / \mathrm{Fe}$ (III)Phen; $E_{\text {adsorption complex }}$ is the total energy of the double supercell of $\mathrm{Mt} / \mathrm{Fe}(\mathrm{III}) \mathrm{Phen}$ hosting the molecule(s) of the adsorbate (naphthalene); $E_{\text {adsorbate }}$ is the total energy of the molecule(s) of the isolated adsorbate species (naphthalene); and $E_{\text {host }}$ is the total energy of the double supercell of $\mathrm{Mt} / \mathrm{Fe}(\mathrm{III}) \mathrm{Phen}$ alone.

\section{RESULTS}

3.1. Selective Trapping of Aromatic Gas Phases by Mt-Fe(III)Phen. Figure 2 shows the amount of benz, Clbenz,

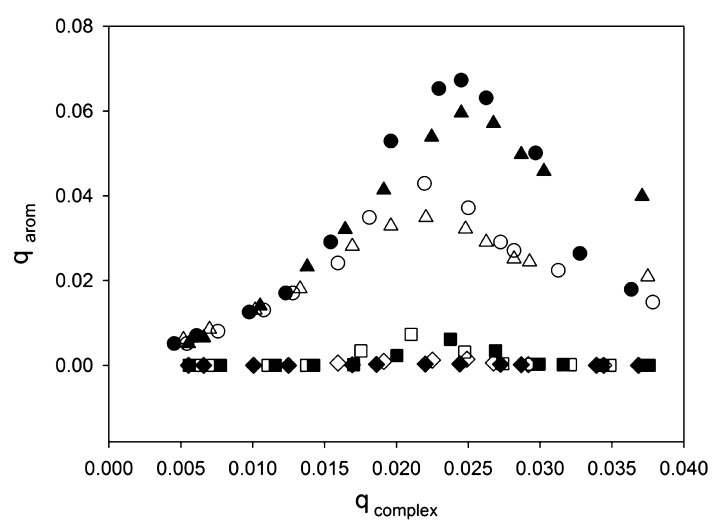

Figure 2. Number of moles of aromatic compounds immobilized at 25 (open symbols) and $50{ }^{\circ} \mathrm{C}$ (filled symbols) per $100 \mathrm{~g}$ of $\mathrm{Mt}-$ $\mathrm{Fe}(\mathrm{III})$ Phen $\left(q_{\text {arom }}\right)$ as a function of $q_{\text {complex }}$ [moles of Fe(III)Phen per $100 \mathrm{~g}$ of $\mathrm{Mt}-\mathrm{Fe}(\mathrm{III}) \mathrm{Phen}]$. (naph $=$ triangle, $\mathrm{Clnaph}=$ circle, benz $=$ diamond, Clbenz $=$ square $)$.

naph, and Clnaph immobilized by Mt-Fe(III)Phen ( $q_{\text {arom }}$, expressed as moles of immobilized species per $100 \mathrm{~g}$ of $\mathrm{Mt}-$ $\mathrm{Fe}(\mathrm{III}) \mathrm{Phen}$ ) as a function of the content of iron complex in the adsorbent material ( $q_{\text {complex }}$ see Experimental Section) after 1 month of exposure to the vapors of the aromatic compounds in a closed box at 25 and $50{ }^{\circ} \mathrm{C}$. The experiments were therefore performed at a constant partial pressure of the aromatic compound corresponding to its vapor pressure at the fixed temperature.

A long time of exposure (1 month) was chosen to ensure that the $\mathrm{Mt}-\mathrm{Fe}(\mathrm{III}) \mathrm{Phen}$ sorbent reached saturation. Moreover, experiments were made at two different temperature values to evaluate the role played by the vapor pressure of the adsorbate. The most notable result is that $\mathrm{Mt}-\mathrm{Fe}$ (III)Phen traps large amounts of naph and Clnaph, which are much larger than Clbenz, while benz is not adsorbed at all. It is worth noting that plain $\mathrm{Mt}$, not functionalized with the iron complex, was not able to entrap any aromatic molecule at 25 and $50{ }^{\circ} \mathrm{C}$. Moreover, at both temperatures, the efficiency of the entrapping process is strongly dependent on the content of iron complex in the adsorbent material (Figure 2). In particular, the plots reporting $q_{\text {arom }}$ versus $q_{\text {complex }}$ for naph and Clnaph at $25{ }^{\circ} \mathrm{C}$ (Figure 2) show a maximum $\left(q_{\mathrm{arom}}^{\max }\right)$ at $q_{\text {complex }}=0.022$ moles of $\mathrm{Fe}(\mathrm{III})$ Phen per $100 \mathrm{~g}$ of $\mathrm{Mt}-$ $\mathrm{Fe}$ (III)Phen (i.e., at about $55 \%$ of the saturation limit for iron complex intercalation in $\mathrm{Mt}$ ), whereas the plots obtained for the same aromatic molecules at $50{ }^{\circ} \mathrm{C}$ (Figure 2) show a maximum at $q_{\text {complex }}=0.025$ moles of $\mathrm{Fe}$ (III)Phen per $100 \mathrm{~g}$ of Mt-Fe(III)Phen (i.e., at about $65 \%$ of the saturation limit for iron complex intercalation in $\mathrm{Mt}$ ). We note that these temperature-dependent $q_{\text {complex }}$ values at which the $q_{\text {arom }}^{\max }$ values are obtained are independent of the nature of the entrapped molecule.

The maximum immobilization capacity $\left(q_{\mathrm{arom}}^{\max }\right)$ strongly increases with temperature. In fact, the $q_{\text {arom }}^{\max }$ value for naph ranges from $0.035 \mathrm{~mol} / 100 \mathrm{~g} \mathrm{Mt}-\mathrm{FePhen}$ at $25{ }^{\circ} \mathrm{C}$ to 0.060 $\mathrm{mol} / 100 \mathrm{~g} \mathrm{Mt}-\mathrm{FePhen}$ at $50{ }^{\circ} \mathrm{C}$ and for Clnaph from 0.043 $\mathrm{mol} / 100 \mathrm{~g} \mathrm{Mt}-\mathrm{FePhen}$ at $25{ }^{\circ} \mathrm{C}$ to $0.067 \mathrm{~mol} / 100 \mathrm{~g} \mathrm{Mt}-$ FePhen at $50{ }^{\circ} \mathrm{C}$. These entrapping performances are remarkable because they were achieved at rather low vapor pressures of adsorbates. At $q_{\text {complex }}$ values higher than that corresponding to $q_{\mathrm{arom}}^{\max }$, the entrapping efficiency clearly decreases and, at the saturation limit in Fe(III)Phen $\left(q_{\text {complex }}\right.$ $=0.038$ ), for naph and Clnaph, the immobilization ability drops at about $60 \%(67 \%)$ and $35 \%(27 \%)$ of the $q_{\text {arom }}^{\max }$ at 25 ${ }^{\circ} \mathrm{C}\left(50{ }^{\circ} \mathrm{C}\right)$. Because of the low efficiency of $\mathrm{Mt}-\mathrm{Fe}(\mathrm{III}) \mathrm{Phen}$ in the immobilization of benz and Clbenz, data on these two aromatic gaseous phases were omitted.

3.2. Temperature Dependence of the Trapping Kinetics for Naphthalene and 1-Chloronaphthalene. The adsorbing rates of naph and Clnaph on Mt-Fe(III)Phen were obtained by measuring the amounts of the aromatic compounds immobilized by $\mathrm{Mt}-\mathrm{Fe}(\mathrm{III}) \mathrm{Phen}_{\text {best25 }}$ and $\mathrm{Mt}-$ $\mathrm{Fe}(\mathrm{III}) \mathrm{Phen}_{\text {best50 }}$ (see Experimental Section) as a function of time at both temperatures (Figure 3). Upon exposure to naph

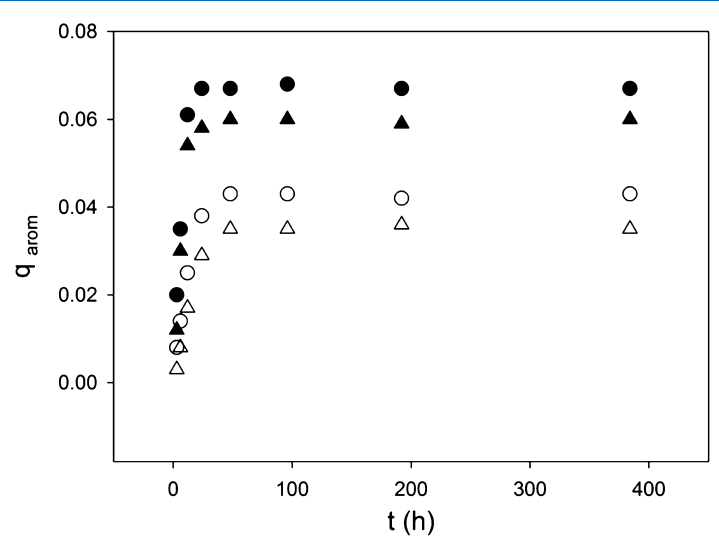

Figure 3. Entrapping kinetics of naph (triangle) and Clnaph (circle) by $\mathrm{Mt}-\mathrm{Fe}(\mathrm{III}) \mathrm{Phen}_{\text {best25 }}$ at 25 (open symbols) and by $\mathrm{Mt}-$ $\mathrm{Fe}$ (III)Phen $\mathrm{Pest50}_{5}$ at $50{ }^{\circ} \mathrm{C}$ (filled symbols). $q_{\text {arom }}$ is the number of moles of immobilized aromatic molecule per $100 \mathrm{~g}$ of $\mathrm{Mt}-$ $\mathrm{Fe}(\mathrm{III})$ Phen. The Mt-Fe(III)Phen adsorbing materials are prepared with $q_{\text {complex }}=0.022$ at $25{ }^{\circ} \mathrm{C}$ and $q_{\text {complex }}=0.025$ at $50{ }^{\circ} \mathrm{C}$ (see Experimental Section).

and Clnaph, the content in the aromatic compound inside

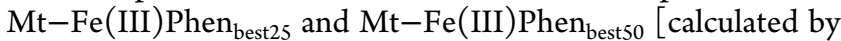
the carbon content exceeding that of $\mathrm{Fe}$ (III)Phen] strongly increases with time to reach a constant value after about $48 \mathrm{~h}$ at $25{ }^{\circ} \mathrm{C}$ and after about $24 \mathrm{~h}$ at $50{ }^{\circ} \mathrm{C}$ for both naph and Clnaph (Figure 3). These data show that the process takes place in a single step and the entrapping process is fast, in particular at $50{ }^{\circ} \mathrm{C}$, according to the increase of the partial pressure and the adsorption rate constant with temperature. The amount of trapped gas phase at $50{ }^{\circ} \mathrm{C}$ is about twice higher than at $25^{\circ} \mathrm{C}$.

3.3. Thermogravimetric Measurements and Regeneration/Reversibility Tests on Mt-Fe(III)Phen-

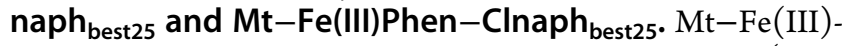
Phen $_{\text {best25 }}$ saturated in naph and Clnaph at $25{ }^{\circ} \mathrm{C}(\mathrm{Mt}-$ 

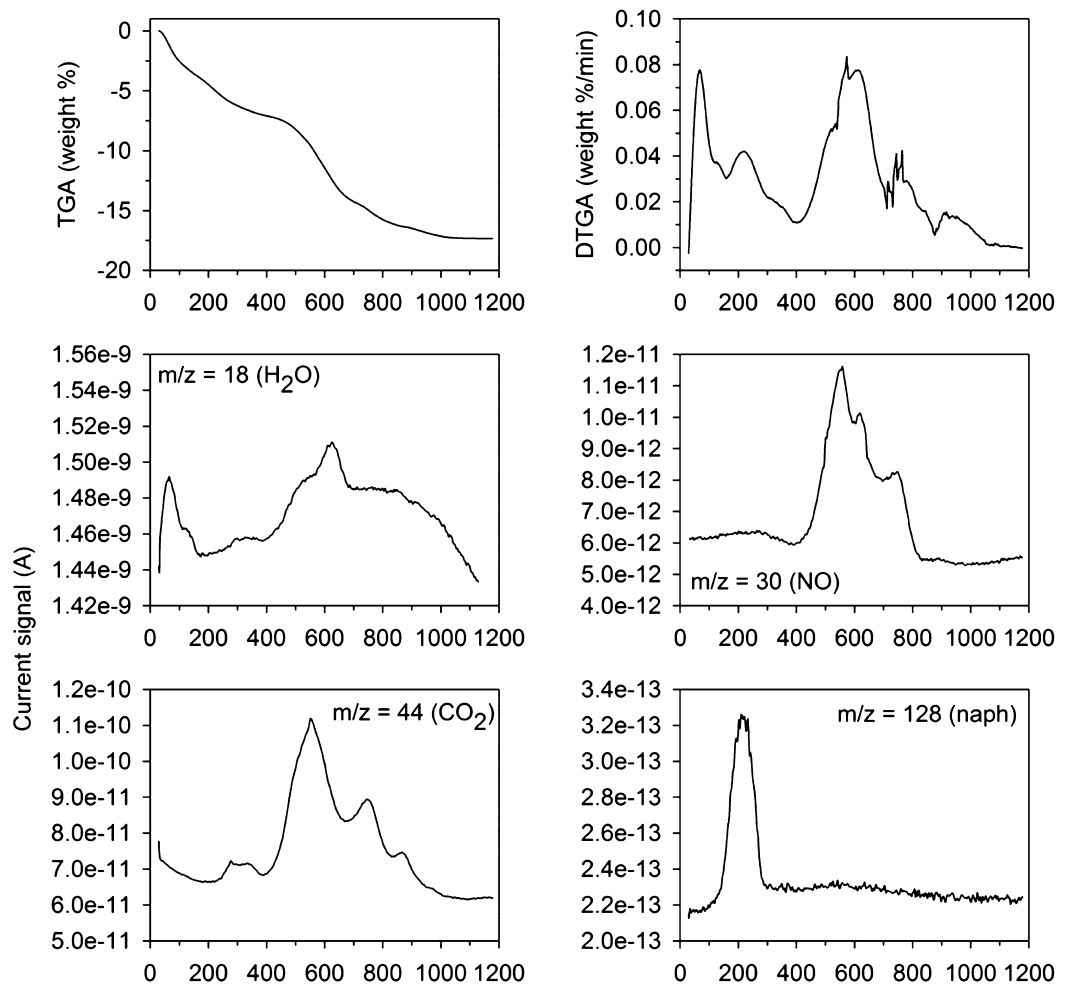

Temperature $\left({ }^{\circ} \mathrm{C}\right)$

Figure 4. Thermogravimetric curves (TGA and DTGA) and mass analysis of the evolved gases as a function of temperature recorded at $m / z=18$ $\left(\mathrm{H}_{2} \mathrm{O}\right), 30\left(\mathrm{NO}\right.$ and $\left.\mathrm{NO}_{2}\right), 44\left(\mathrm{CO}_{2}\right)$, and 128 (naph) of Mt-Fe(III)Phen-naph best25; $q_{\text {complex }}=0.022$ moles of Fe(III)Phen per $100 \mathrm{~g}$ Mt$\mathrm{Fe}(\mathrm{III})$ Phen corresponding to the maximum immobilization capacity at $25{ }^{\circ} \mathrm{C}$.

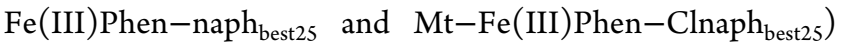
were characterized by TGA and MS-EGA, respectively, to determine the temperature of desorption and the nature of the released species (Figures 4 and 5). The thermal behavior of Mt-Fe(III)Phen alone was characterized previously. ${ }^{10}$ After exposure to the aromatic molecules, major changes in TGA [(and its first derivative curve, differential TGA (DTGA)] were observed in the temperature range $110-300{ }^{\circ} \mathrm{C}$ (Figures 4 and 5). In particular, the DTGA profiles of $\mathrm{Mt}-$

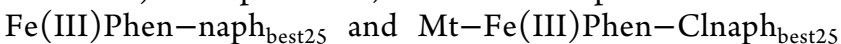
show a well-defined peak at $T=70{ }^{\circ} \mathrm{C}$ and a shoulder at about $135{ }^{\circ} \mathrm{C}$ that are related to the dehydration of the interlayer $\left(\mathrm{H}_{2} \mathrm{O}\right.$ release, $\left.m / z=18\right)$, already observed for $\mathrm{Mt}-$ $\mathrm{Fe}(\mathrm{III})$ Phen alone. ${ }^{10} \mathrm{~A}$ further noticeable thermal effect appears at about $220{ }^{\circ} \mathrm{C}$ for $\mathrm{Mt}-\mathrm{Fe}$ (III)Phen-naph $\mathrm{best25}_{\text {and }}$ at $205{ }^{\circ} \mathrm{C}$ (the peak also shows a well-defined shoulder at 240 ${ }^{\circ} \mathrm{C}$ ) for $\mathrm{Mt}-\mathrm{Fe}(\mathrm{III}) \mathrm{Phen}-\mathrm{Clnaph}_{\text {best25. This is not observed }}$ for $\mathrm{Mt}-\mathrm{Fe}$ (III)Phen and can be related to the release of the undecomposed aromatic molecule (naph release, $m / z=128$, between 150 and $290{ }^{\circ} \mathrm{C}$; Clnaph release, $\mathrm{m} / z=162$ and 127 after the loss of $\mathrm{Cl}$, between 160 and $340{ }^{\circ} \mathrm{C}$ ). At temperatures higher than $350{ }^{\circ} \mathrm{C}$, the DTGA profiles closely resemble that obtained for $\mathrm{Mt}-\mathrm{Fe}$ (III)Phen alone and correspond to the thermal decomposition of the iron complex and, afterward, to Mt dehydroxylation. ${ }^{10}$ The analysis of the thermogravimetric profiles coupled with the MS-EGA shows that within the temperature range $20-350{ }^{\circ} \mathrm{C}$, the mass loss due to dehydration is partially overlapped to the desorption of the aromatic molecules. In the DTGA curves, however, the peaks corresponding to the two processes are well resolved, allowing assignment of the first process (at $T$ about $70{ }^{\circ} \mathrm{C}$ ) to the emission of the interlayer water and the second mass loss (at about $200-220{ }^{\circ} \mathrm{C}$ ) to that of the aromatic compounds. In $\mathrm{Mt}-\mathrm{Fe}$ (III)Phen, the loss of interlayer water was previously quantified being about $5.46 \%{ }^{10}$ the contributions in mass loss due to water and aromatic molecule can be evaluated by TGA: for $\mathrm{Mt}-\mathrm{Fe}$ (III)Phen- naph $_{\text {best25 }}$, these contributions are $2.96 \pm$ $0.26 \%$ of $\mathrm{H}_{2} \mathrm{O}$ and $4.12 \pm 0.14 \%$ of naphthalene, while for $\mathrm{Mt}-\mathrm{Fe}(\mathrm{III}) \mathrm{Phen}-\mathrm{Clnaph}_{\text {best25}}$, they are $3.16 \pm 0.24 \%$ of $\mathrm{H}_{2} \mathrm{O}$ and $6.21 \pm 0.48 \%$ of 1 -chloronaphthalene.

The contents in the aromatic compound determined by TGA $(0.033 \pm 0.002 \mathrm{~mol} / 100 \mathrm{~g} \mathrm{Mt}-\mathrm{Fe}(\mathrm{III})$ Phen for naph and $0.039 \pm 0.003 \mathrm{~mol} / 100 \mathrm{~g} \mathrm{Mt}-\mathrm{Fe}(\mathrm{III})$ Phen for Clnaph) are in good agreement with those calculated by elemental analyses $(0.035 \pm 0.003 \mathrm{~mol} / 100 \mathrm{~g} \mathrm{Mt}-\mathrm{Fe}(\mathrm{III}) \mathrm{Phen}$ for naph and $0.043 \pm 0.002 \mathrm{~mol} / 100 \mathrm{~g} \mathrm{Mt}-\mathrm{Fe}(\mathrm{III}) \mathrm{Phen}$ for Clnaph both at $25{ }^{\circ} \mathrm{C}$ ). The release at relatively low temperature of the intact aromatic compound indicates that $\mathrm{Mt}-\mathrm{Fe}$ (III)Phen can be used several times as the adsorbent material. Mt$\mathrm{Fe}(\mathrm{III}) \mathrm{Phen}-$ naph $_{\text {best25 }}$ and $\mathrm{Mt}-\mathrm{Fe}$ (III)Phen-Clnaph $\mathrm{best25}_{\text {- }}$ were heated at 160,180 , and $200{ }^{\circ} \mathrm{C}$ to optimize the conditions for material regeneration, in particular, to determine the lowest temperature at which a complete and quick removal of the aromatic compound is possible. In fact, Figures 4 and 5 show that the maximum rates of the release of the aromatic compounds are reached at 220 and $205{ }^{\circ} \mathrm{C}$ for naph and Clnaph, respectively, but the release processes already start at about $160{ }^{\circ} \mathrm{C}$.

The changes in the content of aromatic molecules at the different temperature values versus time are reported in Figure 6 for Mt-Fe(III)Phen-naph ${ }_{\text {best25 }}$ and $\mathrm{Mt}-\mathrm{Fe}(\mathrm{III}) \mathrm{Phen}-$

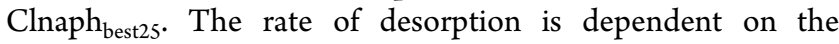



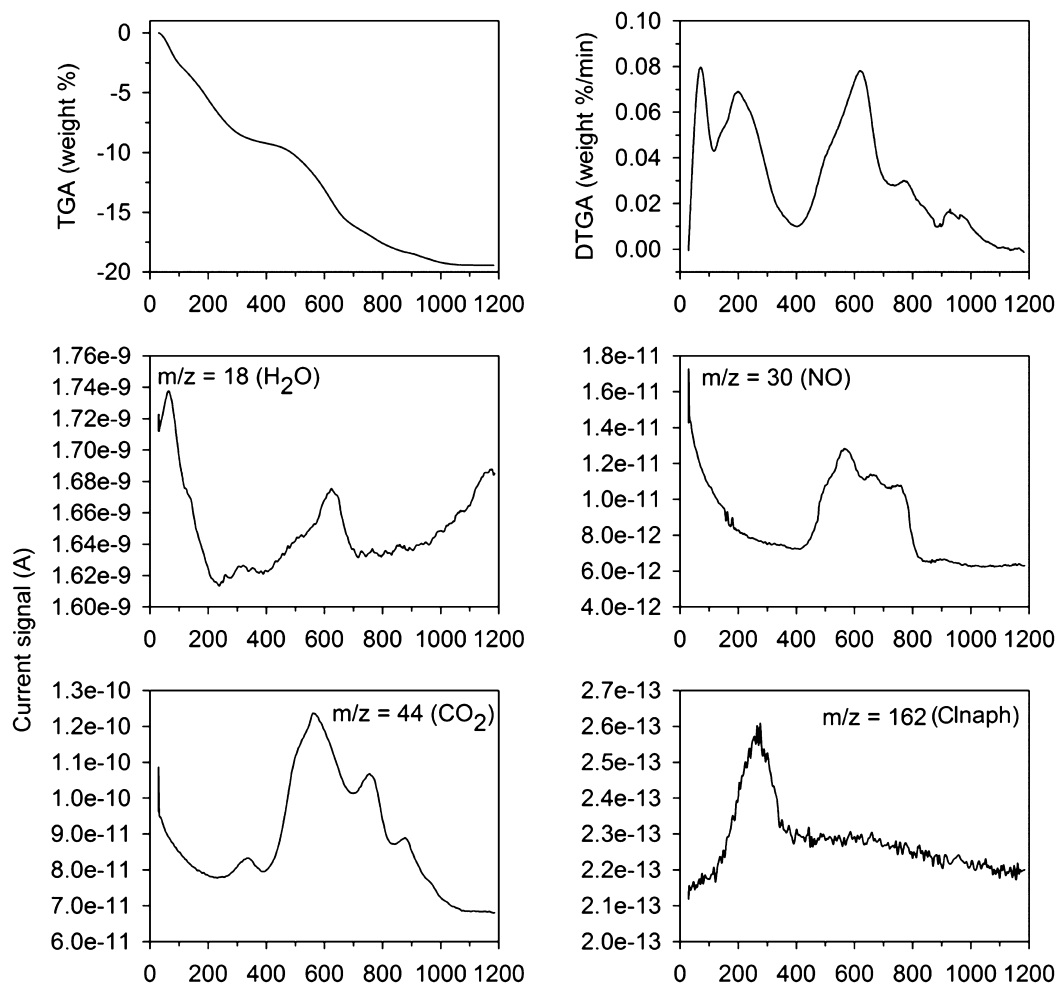

Temperature $\left({ }^{\circ} \mathrm{C}\right)$

Figure 5. Thermogravimetric curves (TGA and DTGA) and mass analysis of the evolved gases as a function of temperature recorded at $m / z=18$ $\left(\mathrm{H}_{2} \mathrm{O}\right), 30\left(\mathrm{NO}\right.$ and $\left.\mathrm{NO}_{2}\right), 44\left(\mathrm{CO}_{2}\right)$, and 162 (Clnaph) of Mt-Fe(III)Phen-Clnaph ${ }_{\text {best25 }}, q_{\text {complex }}=0.022$ moles of Fe(III)Phen per $100 \mathrm{~g} \mathrm{Mt}-$ $\mathrm{Fe}(\mathrm{III})$ Phen corresponding to the maximum immobilization capacity at $25{ }^{\circ} \mathrm{C}$.
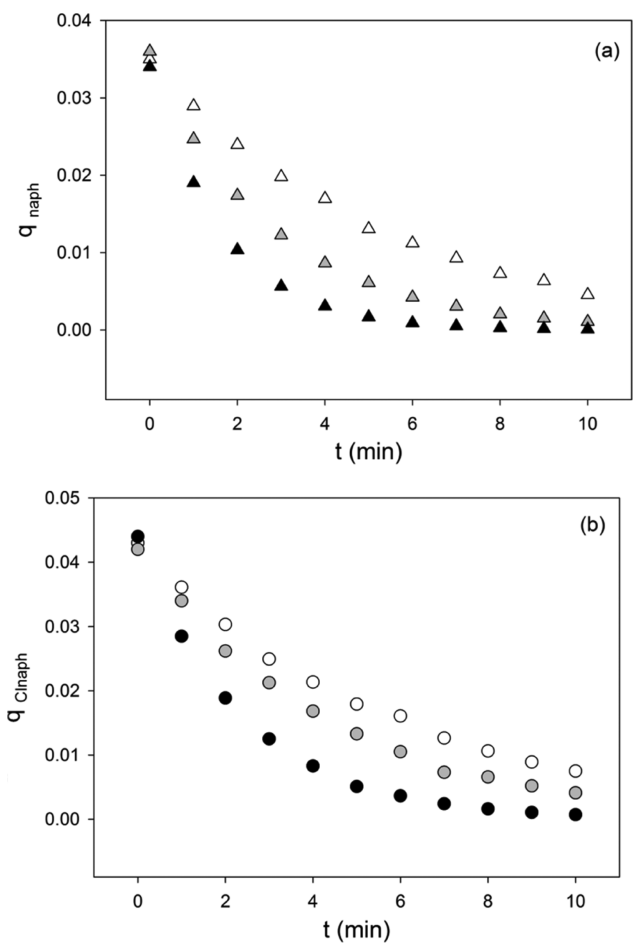

Figure 6. Plot of moles of the aromatic compound per $100 \mathrm{~g}$ of the adsorbing material $(q)$ vs time for $\mathrm{Mt}-\mathrm{Fe}(\mathrm{III}) \mathrm{Phen}-\mathrm{naph}_{\mathrm{best25}}$ (a) and $\mathrm{Mt}-\mathrm{Fe}(\mathrm{III}) \mathrm{Phen}-\mathrm{Clnaph}_{\text {best25 }}$ (b) treated at different temperature values: $T=160$ (white), 180 (gray), and $200^{\circ} \mathrm{C}$ (black); $q_{\text {complex }}$ $=0.022$ moles of FePhen per $100 \mathrm{~g} \mathrm{Mt}-\mathrm{Fe}(\mathrm{III})$ Phen corresponding to the maximum immobilization capacity. treating temperature; at all the temperatures, however, complete desorption can be obtained. In particular, at 200 ${ }^{\circ} \mathrm{C}$ after $10 \mathrm{~min}$ a completely desorption of naph and Clnaph

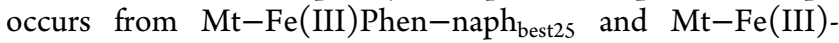

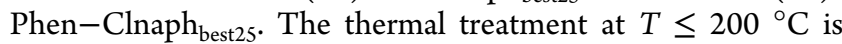
fully reversible for at least 20 cycles, that is, the hybrid material can thermally release and, afterward, uptake the aromatic compound again in the same amount and with a similar time course (Figure 7).

3.4. ${ }^{1} \mathrm{H}$ and ${ }^{13} \mathrm{C}$ CP-MAS NMR Characterization of MtFe(III)Phen Exposed to Naphthalene and 1-Chloronaphthalene. ${ }^{1} \mathrm{H}$ NMR spectra (Figure 8) of the samples exposed

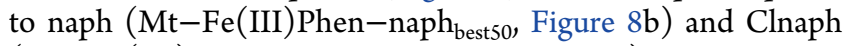

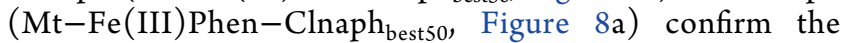
presence of the aromatic molecules immobilized inside $\mathrm{Mt}-$ $\mathrm{Fe}(\mathrm{III}) \mathrm{Phen}_{\text {best50. In fact, together with signals of structural }}$ hydroxyl protons at 2.8 and $1.4 \mathrm{ppm}$, a signal at $7.4 \mathrm{ppm}$ appears after exposure to naph, whereas a resonance at 7.4 and a shoulder at $8.2 \mathrm{ppm}$ are observed in the case of Clnaph. These chemical shifts parallel those observed in solution for the two host molecules. ${ }^{22}$ Both spectra are quite different from that of $\mathrm{Mt}-\mathrm{Fe}$ (III)Phen ${ }_{\text {best50 }}$ (Figure 8c). The same holds for ${ }^{13} \mathrm{C}$ CP-MAS NMR spectra (Figure 9), which are both dominated by a signal at 126.6 and $127.5 \mathrm{ppm}$ for the samples exposed to naph and Clnaph, respectively.

The comparison between the ${ }^{1} \mathrm{H}$ NMR spectral profiles of

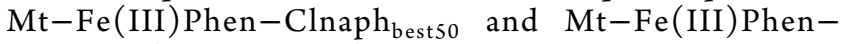
naph $_{\text {best50 }}$ (inset Figure 8) shows that Clnaph signals at 8.2 and $7.4 \mathrm{ppm}$ slightly exceed that of naph at $7.4 \mathrm{ppm}$. Deconvolution of ${ }^{1} \mathrm{H}$ NMR spectra allows to derive a Clnaph/ naph molar ratio of about 1.14, in fair agreement with that 

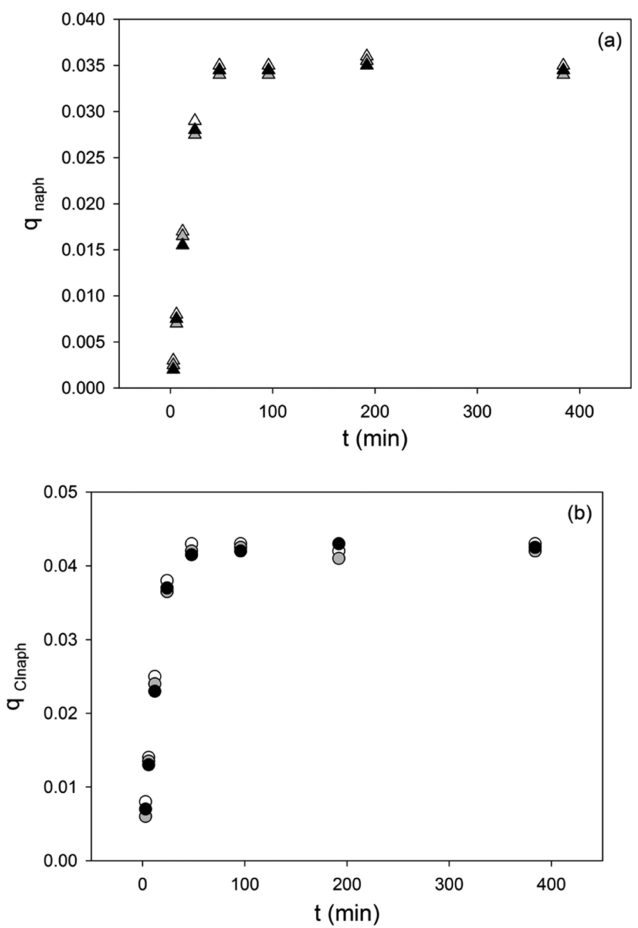

Figure 7. Entrapping kinetics of naph (a) and Clnaph (b) by Mt-

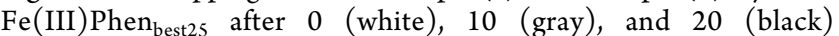
desorption/adsorption cycles; desorption processes were made at $T$ $=200{ }^{\circ} \mathrm{C}$ for $10 \mathrm{~min} . q_{\text {complex }}=0.022$ moles of $\mathrm{Fe}(\mathrm{III})$ Phen per $100 \mathrm{~g}$ $\mathrm{Mt}-\mathrm{Fe}(\mathrm{III}) \mathrm{Phen}$ corresponding to the maximum immobilization capacity.

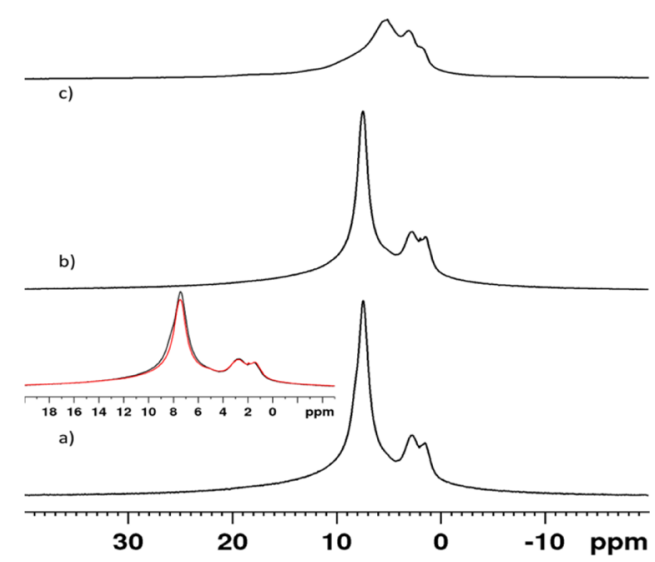

Figure 8. ${ }^{1} \mathrm{H}$ NMR spectra of (a) Mt-Fe(III)Phen-Clnaph ${ }_{\text {best50 }}$ (b) $\mathrm{Mt}-\mathrm{Fe}$ (III)Phen-naph best50, and (c) Mt-Fe(III)Phen $_{\text {best50. The }}$. The overlapped spectra of $\mathrm{Mt}-\mathrm{Fe}$ (III)Phen-Clnaph best50 (black) and

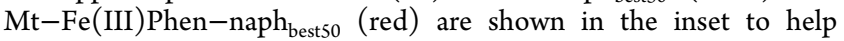
comparison.

obtained by elemental analysis (from Figure 2, at $50{ }^{\circ} \mathrm{C}$ : $\left.q_{\text {Clnaph }}^{\max } / q_{\text {naph }}^{\max }=0.067 / 0.060=1.12\right)$. Structural hydroxyl protons are found to be slightly shielded with respect to those of $\mathrm{Mt}-\mathrm{Fe}(\mathrm{III}) \mathrm{Phen}_{\text {best50 }}$ (3.2 and $1.9 \mathrm{ppm}$ ) and even to those of Mt itself (3.0 and $1.7 \mathrm{ppm}){ }^{19}$

3.5. Computational Simulation of the Interlayer of Mt-Fe(III)Phen Saturated with Naphthalene. The modeling of the adsorbate gaseous phases into Mt-Fe(III)Phen was reported only for naphthalene. The adsorbate molecules, naphthalene and naphthalene dimer, were included in a cubic periodical box of $20 \times 20 \times 20 \AA$. In the naphthalene

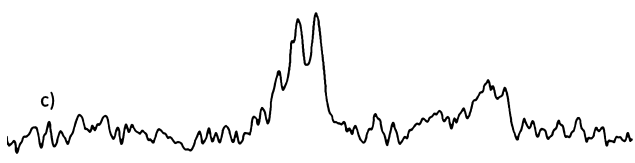

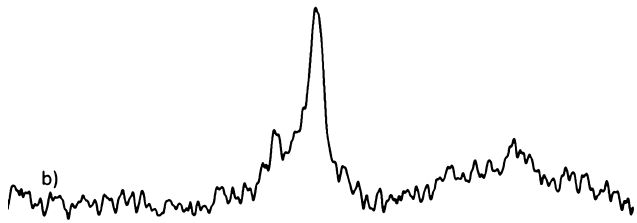

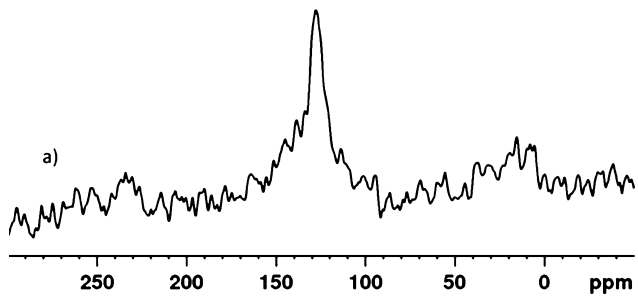

Figure 9. ${ }^{13} \mathrm{C}$ CP-MAS NMR spectra of (a) Mt-Fe(III)Phen-

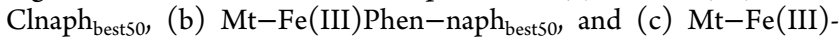
Phen $_{\text {best50 }}$.

dimer, both aromatic rings were parallel and with the same orientation at a distance of $4 \AA$. The optimization of this dimer maintained parallel both aromatic rings with one ring rotated $90^{\circ}$ with respect to another.

By placing one naphthalene molecule between both phenanthroline complexes in a parallel disposition with respect to the phenanthroline rings and the (001) clay surface, the optimization yielded a structure with the naphthalene molecule inclined between both phenanthroline complexes and not intercalated inside the phenanthroline rings (Figure 10a). The shortest distances between the naphthalene $\mathrm{H}$ atoms and the phenanthroline $\mathrm{C}$ atoms are at $3.5 \AA$. The adsorption energy was $-23.75 \mathrm{kcal} / \mathrm{mol}$, indicating that this adsorption is energetically favorable.

Two naphthalene molecules at $3.6 \AA$ in a parallel disposition were also placed in a similar initial position as above, parallel to the clay surface. The optimized structure showed that both adsorbates remained parallel at $3.5 \AA$ and inclined with respect to the phenanthroline complexes at 2.4-3.3 $\AA$ between naphthalene and phenanthroline rings (Figure 10b). Starting with the naphthalene molecules placed separately, one close to the clay surface and another in the center of the interlayer space, the optimization yielded the same above structure. The adsorption energy was $-45.4 \mathrm{kcal} / \mathrm{mol}$, indicating also a highly favorable process.

Besides, another initial configuration was considered, placing both naphthalene molecules in a perpendicular disposition with respect to the mineral surface. The optimization of this structure showed that the adsorbates remained in the same perpendicular disposition with respect to the (001) clay surface (Figure 10c). The naphthalene rings remained parallel at 3.45 A. The distances between the naphthalene and phenanthroline rings are at 2.28-2.70 $\AA$. Besides, a certain interaction between the naphthalene $\mathrm{H}$ atom and the mineral surface basal $\mathrm{O}$ atoms is observed at $2.6 \AA$. The adsorption energy was higher, -52.16 $\mathrm{kcal} / \mathrm{mol}$. These short intermolecular distances explain the higher adsorption energy of this model.

By taking into account that the amount of naphthalene found experimentally by TGA in this solid Mt-Fe(III)Phennaph $_{\text {best25 }}$ was $4.12 \%$, this can be considered an adsorption of 

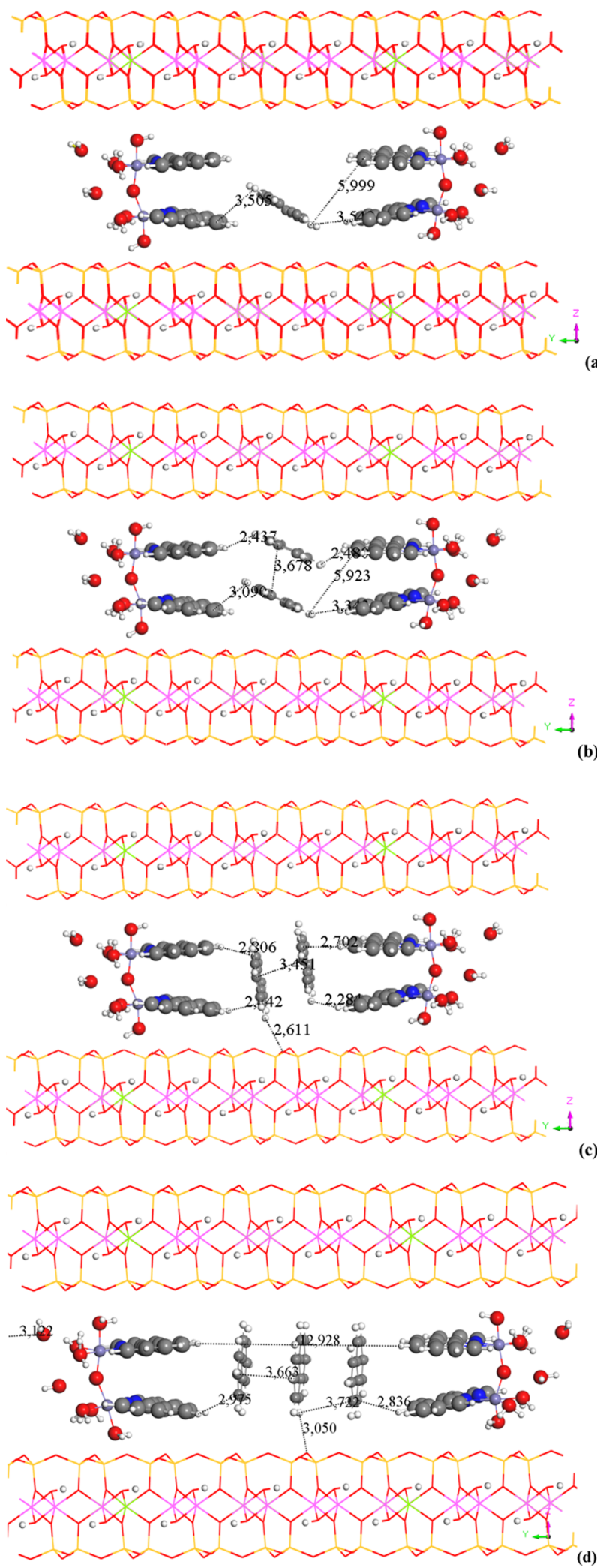

Figure 10. Molecular structure of the $3 \times 4 \times 1$ supercell of Mt with two $\mathrm{Fe}(\mathrm{III})$ Phen complexes with eight water molecules per $\mathrm{Fe}$ complex along with one (a) and two in parallel (b) and two in perpendicular (c) and three in perpendicular (d) disposition with respect to the mineral surface, adsorbed naphthalene molecules.

1.5 molecules of naphthalene per $\mathrm{Fe}$ complex. Then, we included three naphthalene molecules in a parallel disposition and placed them perpendicularly with respect to the (001) clay surface (Figure 10d). After the optimization, all naphthalene molecules remained parallel with inter-ring distances of 3.66$3.70 \AA$ and perpendicular to the (001) plane of the clay mineral. The shortest distances between the naphthalene rings and the phenanthroline rings are 2.84-2.98 $\AA$. In the same way, this trimer of naphthalene was optimized in a $20 \times 20 \times$ $20 \AA$ box maintaining all aromatic rings parallel with the middle ring rotated $90^{\circ}$ with respect to others. This rotation was not observed when this trimer is intercalated in the clay interlayer space. The adsorption energy was $\Delta E=-72.89$ $\mathrm{kcal} / \mathrm{mol}$, indicating an energetically favorable adsorption process according to the above results.

\section{DISCUSSION}

Mt-Fe(III)Phen is able to rapidly immobilize a large amount of naph and Clnaph but shows an extremely low affinity toward benz and its chloro-derivative. Previous studies have shown that $\mathrm{Mt}$ adsorbs $\mathrm{Fe}$ (III)Phen in excess (twice the cation exchange capacity, CEC) and induces a structuring of the interlayer as a function of the amount of the immobilized complex. $^{10}$ The interaction of $\mathrm{Mt}-\mathrm{Fe}$ (III)Phen with aromatic species in the gas phase is likely to be controlled by the presence and disposition of the aromatic moiety of the iron complex mainly through the shaping of the interlayer volume with hydrophobic channels and holes having suitable dimensions for guest molecules. If the holes are large enough, $\pi$-stacking interactions could be established between adjacent naphthalene rings. Molecules with large aromatic regions, such as naphthalenes, yield stronger intermolecular stacking interactions than benzene and its derivatives, which are also more volatile. These reasons would explain the larger affinity of $\mathrm{Mt}-\mathrm{Fe}(\mathrm{III}) \mathrm{Phen}$ for naphthalenes than benzenes: maybe shape and dimensions of the array made by three naphthalene molecules, with strong $\pi$ interactions, fit better with the available hydrophobic nanospaces than the benzene-type ones. This selectivity is a step ahead with respect to classical organoclays, which, albeit showing highly hydrophobic interlayers, are not selective.

This view is supported by the observation that the amount of adsorbed molecules $\left(q_{\text {arom }}\right)$ as a function of the composition of the adsorbent hybrid material $\left(q_{\text {complex }}\right)$ shows a maximum. In fact, the amount of immobilized aromatic derivative is controlled by two opposite contributions: the available volume in the interlayer and the amount of aromatic moieties with which the adsorbate can interact. The peak of maximum adsorption corresponds to a slightly higher amount of the stoichiometric proportion related with the CEC capacity, named semi-saturated sample in previous work. ${ }^{10,11}$ This excess of $\mathrm{Fe}$ complex acts as a pillaring agent taking into account previous X-ray diffraction profiles, where the $d(001)$ spacing increased with a partial excess of Fe complex. ${ }^{10}$ This corroborates previous molecular modeling work where these excess $\mathrm{Fe}$ complexes have a perpendicular disposition with respect to the interlayer surface, acting as pillars in the interlayer space. ${ }^{11}$ These pillars do not avoid the entrance of aromatics and the increase of $d(001)$ spacing and internal free volume facilitates a slightly higher adsorption capacity.

The maximum adsorption of naph and Clnaph at $50{ }^{\circ} \mathrm{C}$ is observed at a $q_{\text {complex }}$ value higher than that determined at 25 ${ }^{\circ} \mathrm{C}$. This result is probably related to the fact that temperature disfavors entropically and enthalpically the adsorption process, which is exothermic. Clnaph is immobilized to a larger extent 
than naph at both temperatures, despite the larger vapor pressure of the latter compound, especially at $50{ }^{\circ} \mathrm{C}$. This effect could be related to the dipole induced by $\mathrm{Cl}$ in the Clnaph molecule. The entrapping efficiency for naph and Clnaph is larger at $50{ }^{\circ} \mathrm{C}$ than at $25{ }^{\circ} \mathrm{C}$. High temperature, although in general disfavors the adsorption processes, increases the vapor pressure of the aromatic molecule, which enhances the entrapment. However, this increase of vapor pressure with the temperature is much higher than the increase of adsorption efficiency (e.g., for Clnaph, $P_{50^{\circ} \mathrm{C}} / P_{25^{\circ} \mathrm{C}}=6.8$, while $\left.q_{50^{\circ} \mathrm{C}}^{\max } / q_{25^{\circ} \mathrm{C}}^{\max }=1.6\right)$. This can indicate that the intercalation of aromatics decreases the entropy, that is, the adsorption has a negative entropy contribution, explaining the lower increase in adsorption efficiency with higher temperature with respect to the higher increase in vapor pressure.

The entrapping performances, achieved at rather low vapor pressures of adsorbates, are similar or even higher than those obtained using other well-known high-performance adsorbing materials such as synthetic zeolites, active carbons, or organoclays. ${ }^{1}$ In organoclays, the intercalation of alkyl chains in the interlayer imparts the material with the ability to bind exogenous molecules through not specific hydrophobic interactions. The material proposed here exploits the structuring effect that the iron complex has on the interlayer ${ }^{10}$ to efficiently bind exogenous aromatic hydrocarbons.

In addition, the immobilization rate is also high at $25^{\circ} \mathrm{C}$ and the hybrid material also proved to be stable over time after treatment at $200{ }^{\circ} \mathrm{C}$ and reusable. Desorption is also fast at 160 ${ }^{\circ} \mathrm{C}$, and the released species is the pristine species. This allows a quantitative recovery of the aromatic species and adsorbent solid.

\section{CONCLUSIONS}

We have shown that Mt-Fe(III)Phen, a hybrid material easily obtained by fast intercalation of the $\mathrm{Fe}$ (III)-Phen complex into $\mathrm{Mt}$, is able to efficiently trap naphthalene and 1chloronaphthalene at the solid/gas interface. This property is related to the strong interactions of these species with the aromatic moiety of the iron complex, providing a stable immobilization. This process occurs at room temperature and its characteristics can be modified changing the composition (iron complex content) of the hybrid material. In fact, the efficiency of $\mathrm{Mt}-\mathrm{Fe}$ (III)Phen as naphthalenes trap is controlled by the saturation level of the complex, which modulates structuration, hydrophobicity, and availability of the aromatic moiety inside the interlayer. In particular, structuration of the interlayer probably results in the formation of a network of strongly hydrophobic channels lined by the phenanthroline moieties of the $\mathrm{Fe}(\mathrm{III}) \mathrm{Phen}$ aggregates. The immobilization is fast and fully reversible: the entrapping material can be thermally regenerated and brought back to its full immobilizing capacity quickly and in mild conditions. The high adsorption efficiency of $\mathrm{Mt}-\mathrm{Fe}(\mathrm{III}) \mathrm{Phen}$ is mainly determined by the unique nanostructure and tailorable properties of the interlayer, which make it suitable for the capture of various aromatic molecules which have a strong environmental impact. Because the mechanism that controls naphthalene immobilization probably involves the formation of stacking interactions between molecules entrapped in hydrophobic interlayer spaces, the structure and the extent of the hydrophobic channels are probably the determinants of the observed entrapping activity of $\mathrm{Mt}-\mathrm{Fe}(\mathrm{III})$ Phen.
The already proved entrapping ability of $\mathrm{Mt}-\mathrm{Fe}(\mathrm{III}) \mathrm{Phen}$ toward thiols and $\mathrm{H}_{2} \mathrm{~S}$ has been here extended to the aromatic molecules of environmental interest. The novelty of the present work is the exploitation of the aromatic moiety of $\mathrm{Fe}$ (III)Phen, which is able to structure the interlayer to form hydrophobic channels which allow the specific entrapping of naphthalene and 1-chloronaphthalene. We are also convinced that it is possible to expand the opportunities offered by this approach employing other ligands with affinity for aromatic moieties and extending the research to the study of the immobilization of other aromatics.

\section{ASSOCIATED CONTENT}

\section{S Supporting Information}

The Supporting Information is available free of charge on the ACS Publications website at DOI: 10.1021/acsomega.9b00335.

Vapor pressures of investigated benzenes and naphthalenes at 25 and $50{ }^{\circ} \mathrm{C}$, respectively (PDF)

\section{AUTHOR INFORMATION}

\section{Corresponding Author}

*E-mail: ignacio.sainz@iact.ugr-csic.es.

\section{ORCID $\odot$}

Elena Castellini: 0000-0002-2933-4405

Daniele Malferrari: 0000-0002-0879-1703

Claro Ignacio Sainz Diaz: 0000-0001-8612-3826

Adele Mucci: 0000-0003-3303-8761

Maria Franca Brigatti: 0000-0002-7526-9931

Marco Borsari: 0000-0002-3612-4764

\section{Author Contributions}

The manuscript was written through contributions of all authors. All authors have given approval to the final version of the manuscript. All the authors contributed equally.

\section{Notes}

The authors declare no competing financial interest.

\section{ACKNOWLEDGMENTS}

The authors are thankful to the University of Modena and Reggio Emilia for FAR 2016 funding program (PAsTIME Project, grant number: FAR2016DIPBORSARI), for the Visiting Professor program, and for the facilities provided by the Centro Interdipartimentale Grandi Strumenti, to MIUR for funding program FFABR 2017, to the Computational Centre of University of Granada and CINECA of Bologna for the high-performance computing service, and to the Andalusian project RMN1897 and the Spanish projects FIS2013-48444C2-2-P and FIS2016-77692-C2-2-P for financial support.

\section{REFERENCES}

(1) Klein, H.; Fuessa, H.; Ernst, S.; Weitkamp, J. Localization of naphthalenes in zeolite HZSM-5 by X-ray powder diffraction and molecular mechanics calculation. Microporous Mesoporous Mater. 1994, 3, 291-304.

(2) Yuan, W.; Yuan, P.; Liu, D.; Yu, W.; Deng, L.; Chen, F. Novel hierarchically porous nanocomposites of diatomite-based ceramic monoliths coated with silicalite-1 nanoparticles for benzene adsorption. Microporous Mesoporous Mater. 2015, 206, 184-193.

(3) Galadima, A.; Muraza, O. Role of zeolite catalysts for benzene removal from gasoline via alkylation: A review. Microporous Mesoporous Mater. 2015, 213, 169-180. 
(4) Chambellan, A.; Chevreau, T.; Khabtou, S.; Marzin, M.; Lavalley, J. C. Acidic sites of steamed HY zeolites, active for benzene self-alkylation and hydrogenation. Zeolites 1992, 12, 306-314.

(5) Koekkoek, A. J. J.; Xin, H.; Yang, Q.; Li, C.; Hensen, E. J. M. Hierarchically structured Fe/ZSM-5 as catalysts for the oxidation of benzene to phenol. Microporous Mesoporous Mater. 2011, 145, 172181.

(6) Tsai, K.-Y.; Wang, I.; Tsai, T.-C. Zeolite supported platinum catalysts for benzene hydrogenation and naphthene isomerization. Catal. Today 2011, 166, 73-78.

(7) Foley, N. J.; Thomas, K. M.; Forshaw, P. L.; Stanton, D.; Norman, P. R. Kinetics of water vapor adsorption on activated carbon. Langmuir 1997, 13, 2083-2089.

(8) Guo, Y.; Li, Y.; Wang, J.; Zhu, T.; Ye, M. Effects of activated carbon properties on chlorobenzene adsorption and adsorption product analysis. Chem. Eng. J. 2014, 236, 506-512.

(9) Brigatti, M. F.; Díaz, C. I. S.; Borsari, M.; Bernini, F.; Castellini, E.; Malferrari, D. Crystal chemical characterization and computational modeling of a $\mu$-oxo Fe(III) complex with 1,10-phenanthroline clarify its interaction and reactivity with montmorillonite. Rend. Fis. Acc. Lincei 2017, 28, 605-614.

(10) Bernini, F.; Castellini, E.; Malferrari, D.; Borsari, M.; Brigatti, M. F. Stepwise structuring of the adsorbed layer modulates the physico-chemical properties of hybrid materials from phyllosilicates interacting with the $\mu$-oxo $\mathrm{Fe}^{+3}$-phenanthroline complex. Microporous Mesoporous Mater. 2015, 211, 19-29.

(11) Sainz-Díaz, C. I.; Bernini, F.; Castellini, E.; Malferrari, D.; Borsari, M.; Mucci, A.; Brigatti, M. F. Experimental and Theoretical Investigation of Intercalation and Molecular Structure of Organo-Iron Complexes in Montmorillonite. J. Phys. Chem. C 2018, 122, 2542225432.

(12) Bernini, F.; Castellini, E.; Malferrari, D.; Castro, G. R.; Sainz Díaz, C. I.; Brigatti, M. F.; Borsari, M. Effective and Selective Trapping of Volatile Organic Sulfur Derivatives by Montmorillonite Intercalated with a $\mu$-oxo $\mathrm{Fe}$ (III)-Phenanthroline Complex. ACS Appl. Mater. Interfaces 2017, 9, 1045-1056.

(13) Malferrari, D.; Castellini, E.; Bernini, F.; Rubio, A. S.; Castro, G. R.; Sainz-Díaz, C. I.; Caleffi, M.; Brigatti, M. F.; Borsari, M. Chemical trapping of gaseous $\mathrm{H}_{2} \mathrm{~S}$ at high and low partial pressures by an iron complex immobilized inside the montmorillonite interlayer. Microporous Mesoporous Mater. 2018, 265, 8-17.

(14) Khan, F. I.; Kr. Ghoshal, A. Removal of Volatile Organic Compounds from polluted air. J. Loss Prev. Process Ind. 2000, 13, 527-545.

(15) The Clay Minerals Society Database, http://www.clays.org/ sourceclays data.html, 2019.

(16) Castellini, E.; Berthold, C.; Malferrari, D.; Bernini, F. Sodium Hexametaphosphate Interaction with 2:1 Clay Minerals Illite and Montmorillonite. Appl. Clay Sci. 2013, 83-84, 162-170.

(17) Mackay, D.; Shiu, W. Y.; Ma, K.-C.; Lee, S. C. Handbook of Physical-Chemical Properties and Environmental Fate for Organic Chemicals, 2nd ed.; Taylor and Francis: Boca Raton, 2006.

(18) Giustetto, R.; Seenivasan, K.; Bonino, F.; Ricchiardi, G.; Bordiga, S.; Chierotti, M. R.; Gobetto, R. Host/Guest Interactions in a Sepiolite-Based Maya Blue Pigment: A Spectroscopic Study. J. Phys. Chem. C 2011, 115, 16764-16776.

(19) Castellini, E.; Malferrari, D.; Bernini, F.; Franca Brigatti, M.; Rafael Castro, G.; Medici, L.; Mucci, A.; Borsari, M. Baseline studies of The Clay Minerals Society Source Clay montmorillonite STx-1b. Clays Clay Miner. 2017, 65, 220-233.

(20) BIOVIA Materials Studio, Version 2018; Dassault Systemes: Vélizy-Villacoublay, France, 2018.

(21) Rappe, A. K.; Goddard, W. A. Charge equilibration for molecular dynamics simulations. J. Phys. Chem. 1991, 95, 3358-3363.

(22) Spectral Database for Organic Compounds; SDBS, http://sdbs. db.aist.go.jp, 2018. 